\title{
NITROGÊNIO EM COBERTURA E QUALIDADE FISIOLÓGICA E SANITÁRIA DE SEMENTES DE PAINÇO (Panicum miliaceum L.) ${ }^{1}$
}

\author{
FABIANA L. ABRANTES ${ }^{2}$, STELA MARIS KULCZYNSKI ${ }^{3}$, \\ ROGÉRIO P. SORATTO ${ }^{4}$, MANOEL MURILO M. BARBOSA ${ }^{5}$
}

\begin{abstract}
RESUMO - O nitrogênio pode influenciar a qualidade das sementes de várias culturas e os seus efeitos variam com as condições ambientais e o estádio de desenvolvimento da planta em que a aplicação é realizada. Porém, pouco se sabe sobre a influência da adubação nitrogenada na qualidade de sementes da cultura do painço (Panicum miliaceum L.). O objetivo neste trabalho foi avaliar o efeito de doses e épocas de aplicação de nitrogênio em cobertura na qualidade fisiológica e sanitária de sementes de painço, cv. AL Tibagi, produzidas em condições de campo. As sementes foram produzidas no período de dezembro de 2005 a fevereiro de 2006 e as avaliações laboratoriais realizadas de março a agosto de 2006. O delineamento experimental foi de blocos ao acaso, em esquema fatorial 4 x 2 , constituído pela combinação de quatro doses $\left(0,30,60\right.$ e $120 \mathrm{~kg} \mathrm{ha}^{-1}$ de N) e duas épocas de aplicação (14 e 28 dias após a emergência - DAE) do fertilizante nitrogenado (uréia) em cobertura, com quatro repetições. A aplicação de $\mathrm{N}$ aumentou o vigor das sementes, expresso pelos testes de envelhecimento acelerado e emergência em campo. A aplicação de nitrogênio aos 28 DAE da cultura do painço proporciona maiores IVE e porcentagem de emergência em campo. A sanidade de sementes de painço não é influenciada pelas doses e épocas de aplicação da adubação nitrogenada.
\end{abstract}

Termos para indexação: adubação nitrogenada, germinação, vigor.

\section{NITROGEN TOP-DRESSING AND THE PHYSIOLOGICAL AND SANITARY QUALITY OF PROSO MILLET (Panicum miliaceum L.) SEEDS}

\begin{abstract}
Nitrogen can influence the seed quality of several crops and its effects vary with the environmental conditions and the plant stage when the nitrogen is applied. However, little is known of the influence of nitrogen fertilization on seed quality in proso millet (Panicum miliaceum L.). The objective of this study was to evaluate the effect of dosages and times of nitrogen top-dressing applications on the physiological and sanitary quality of proso millet, cv. AL Tibagi, seeds grown under field conditions. Seeds were produced between December, 2005 and February, 2006 and laboratory evaluations between March and August, 2006. A completely randomized block design in a 4x2 factorial was used, with a combination of four dosages $\left(0,30,60\right.$, and $120 \mathrm{~kg} \mathrm{ha}^{-1}$ of $\left.\mathrm{N}\right)$ and two application times (14 and 28 days after emergence) of nitrogen fertilizer (urea) in top-dressing with four replications. Nitrogen application increased seed vigor, expressed by the tests of accelerated ageing and field emergence.
\end{abstract}

\footnotetext{
${ }^{1}$ Submetido em 26/10/2009. Aceito para publicação em 29/04/2010. Parte do Trabalho de Graduação da primeira autora apresentado à UEMS.

${ }^{2}$ Eng. Agr., Pós-graduanda em Agronomia, FEIS/UNESP, Rua D, n ${ }^{\circ}$ 91, Jd. Novo Horizonte, CEP 15.385-000, Ilha Solteira-SP. Email: fabianaabrantes@hotmail.com.

${ }^{3}$ Eng. Agr., Dr. Professora do Departamento de Agronomia, CESNORS/ UFSM, Linha Sete de Setembro s/n, BR 386 - km 40, CEP 98400-000,
}

Frederico Westphalen-RS. Email: stelamk@terra.com.br.

${ }^{4}$ Eng. Agr., Dr. Professor Assistente do Departamento de Produção Vegetal, FCA/UNESP, Caixa Postal 237, CEP 18.610-307, Botucatu-SP. Email: soratto@fca.unesp.br.

${ }^{5}$ Granduando em Agr. da UEMS, Unidade Universitária de Cassilândia, MS. E-mail: manoel_agro@hotmail.com. 
Nitrogen application of proso millet at 28 DAE results in higher IVE and percentage of field emergence. The sanitary quality of Proso millet seed was not influenced by the dosages and times of application of the nitrogen fertilization.

Index terms: nitrogen fertilization, germination, vigor.

\section{INTRODUÇÃO}

O painço (Panicum miliaceum L.) foi o mais antigo cereal utilizado pelo homem, depois do trigo e da cevada (Kalinova e Moudry, 2006). É uma cultura que apresenta ciclo muito curto e vem sendo cultivada em algumas regiões do Estado de São Paulo e Mato Grosso do Sul com o objetivo de exploração dos grãos, para utilização na alimentação animal, principalmente de pássaros em cativeiro, substituindo o alpiste (Furuhashi, 1995; Zancanella et al., 2003), na indústria cervejeira misturado em pequena proporção com a cevada (Lima et al., 2000) e como espécie produtora de palha para o plantio direto e adubo verde (Zancanella et al., 2006).

De acordo com Zancanella et al. (2006), o painço apresenta como vantagens o baixo custo e a rapidez de formação abundante de palha e produção de grãos, podendo ser semeado durante praticamente todo o ano, desde que haja umidade suficiente no solo e não existam riscos de geadas, sendo a safra normal de setembro a dezembro e a safrinha de janeiro a março.

Os nutrientes apresentam papel relevante durante as fases de formação, desenvolvimento e maturação das sementes, principalmente na constituição das membranas e no acúmulo de lipídios, carboidratos e proteínas (Sá, 1994). Quanto ao nitrogênio (N), é conhecida sua importância no metabolismo das plantas, participando como constituinte de moléculas de proteínas, coenzimas, ácido nucleicos, clorofila e outras enzimas, controlando o desenvolvimento das plantas (Malavolta et al., 1997). Portanto, a aplicação de fertilizantes nitrogenados pode afetar, além do crescimento da planta e da produtividade, também a qualidade do grão (Didonet, 1994), já que os efeitos da nutrição adequada se refletem principalmente no tamanho e peso das sementes (Marcos Filho, 2005), na formação do embrião e dos cotilédones com resultados eficazes sobre a qualidade fisiológica e o vigor das sementes (Teixeira et al., 2005).

A qualidade da semente é fator resultante da ação de diversas características, tais como viabilidade, vigor, teor de água, maturidade, danos mecânicos, infecção por patógenos, tamanho, longevidade, entre outros (Popinigis, 1985). Além disso, Carvalho e Nakagawa (2000) complementam que a qualidade da semente é expressão da interação dos componentes genético, físico, sanitário e fisiológico. Dessa forma, a nutrição da planta pode ser um fator limitante na produção de sementes com qualidade adequada, sendo que o $\mathrm{N}$ tem papel importante, pois seus efeitos variam com as condições ambientais e com o estádio de desenvolvimento da planta em que é aplicado (Carvalho e Nakagawa, 2000), interferindo na qualidade das sementes (Condé e Garcia, 1988a, b; Meireles et al., 2009; Toledo et al., 2009).

Concentrações elevadas de $\mathrm{N}$ reduzem a produção de compostos fenólicos, que possuem ação fungistática, e a lignificação das folhas, diminuindo a resistência aos patógenos obrigatórios, e não apresentando ação sobre aqueles que são facultativos (Marschner, 1995). A infecção pelas doenças fúngicas é favorecida pelo $\mathrm{N}$, pois este aumenta a concentração de aminoácidos e de amidas no apoplasto e nas células do mesófilo foliar, substâncias que, têm maior influência que os açúcares na germinação e no desenvolvimento de conídios. $\mathrm{O}$ aspecto nutricional da planta apresenta um efeito indireto sobre a incidência de patógenos em sementes, uma vez que uma das formas de contaminação das sementes é no campo. Assim plantas crescendo em solos com estresse nutricional são mais suscetíveis a os patógenos do que plantas crescendo em solo com fertilidade balanceada.

No entanto, os efeitos da adubação nitrogenada sobre a qualidade fisiológica e sanitária de sementes são um tanto controversos, mesmo em culturas como milho, arroz e trigo, ficando evidente a necessidade de mais estudos sobre a relação entre adubação/nutrição e a produção de sementes de alta qualidade (Vieira et al., 1995; Oliveira, et al., 2003).

Soratto et al. (2004) observaram aumentos na altura da planta, número de colmos por planta e produtividade de grãos de dois cultivares de painço em função da aplicação de $\mathrm{N}$ em cobertura sob condições de casa de vegetação. Soratto et al. (2007) também obtiveram incremento não crescimento e produtividade da cultura do painço, 
mediante aplicação de $\mathrm{N}$ em cobertura em condições de campo. Contudo, existe carência de informações com relação ao efeito do manejo da adubação nitrogenada na qualidade e sanidade das sementes produzidas.

O objetivo no presente trabalho foi avaliar o efeito de doses e épocas de aplicação de $\mathrm{N}$ em cobertura na qualidade fisiológica e sanitária de sementes de painço cv. AL Tibagi, produzidas em condições de campo.

\section{MATERIAL E MÉTODOS}

O experimento de campo foi conduzido em área experimental pertencente à Universidade Estadual de Mato Grosso do Sul - UEMS, Unidade Universitária de Cassilândia, município de Cassilândia, MS (1905'25" $\mathrm{S}, 51^{\circ} 48^{\prime} 52^{\prime}$ W, com altitude de $508 \mathrm{~m}$ ). O solo do local é um Neossolo Quartzarênico, cujas características granulométricas são: 877,20 e $103 \mathrm{~g}$. $\mathrm{kg}^{-1}$ de areia, silte e argila, respectivamente.

Antes da instalação do experimento foi realizada amostragem de solo para a determinação das características químicas, na camada de $0-0,20 \mathrm{~m}$, de acordo com método proposto por Raij et al. (2001), cujos resultados foram: matéria orgânica $17,6 \mathrm{~g} \mathrm{dm}^{-3}, \mathrm{pH}\left(\mathrm{CaCl}_{2}\right) 4,8 ; \mathrm{P} \mathrm{3,8} \mathrm{mg}$ . $\mathrm{dm}^{-3} ; 1,2 ; 12,6 ; 5,2$ e $21,9 \mathrm{mmol}_{\mathrm{c}} \mathrm{dm}^{-3}$ respectivamente de $\mathrm{K}, \mathrm{Ca}, \mathrm{Mg}$ e $\mathrm{H}+\mathrm{Al}$, e $46 \%$ de saturação por bases.

$\mathrm{O}$ experimento foi instalado em área anteriormente cultivada com pastagem. Em outubro de 2005 foi realizada na área calagem, aplicando-se $1.400 \mathrm{~kg}$. ha ${ }^{-1}$ de calcário dolomítico. Após a distribuição, o calcário foi incorporado com uma gradagem pesada e uma gradagem leve. Às vésperas da semeadura, o solo foi preparado com duas gradagens leves.

O delineamento experimental utilizado foi o de blocos ao acaso, no esquema fatorial 4 x 2 , com quatro repetições. Os tratamentos foram constituídos pela combinação de quatro doses de $\mathrm{N}\left(0,30,60\right.$ e $120 \mathrm{~kg}$. ha- $\left.{ }^{-1}\right)$ em cobertura, tendo como fonte a uréia, e duas épocas de aplicação (14 dias após a emergência (DAE), ou seja, no estádio de perfilhamento, e $28 \mathrm{DAE}$, no estádio de emborrachamento). Cada parcela foi constituída por cinco linhas de 4,0 m de comprimento. A área útil foi constituída pelas três linhas centrais, desprezando-se $0,50 \mathrm{~m}$ em ambas as extremidades de cada linha.

A adubação de semeadura constou da aplicação, em todos os tratamentos, de $15 \mathrm{~kg}$. ha ${ }^{-1}$ de N na forma de uréia, $60 \mathrm{~kg}$. ha ${ }^{-1}$ de $\mathrm{P}_{2} \mathrm{O}_{5}$ na forma de superfosfato simples, $40 \mathrm{~kg}$. ha- $\mathrm{de}_{2} \mathrm{O}$ na forma de cloreto de potássio e $20 \mathrm{~kg}$. ha ${ }^{-1}$ de F.T.E. BR-12
(9,0\% de $\mathrm{Zn}, 1,8 \%$ de $\mathrm{B}, 0,8 \%$ de $\mathrm{Cu}, 3,0 \%$ de $\mathrm{Fe}, 2,0 \%$ de Mn e $0,1 \%$ de Mo). A distribuição da adubação básica foi realizada com uma semeadora-adubadora tratorizada, regulada no espaçamento de $0,40 \mathrm{~m}$ e a profundidade de 0,08 $\mathrm{m}$. A semeadura foi realizada manualmente, em sulcos de $0,02 \mathrm{~m}$ de profundidade, abertos exatamente sobre as linhas onde havia sido distribuída a adubação, em 30/11/2005, utilizando o cultivar AL Tibagi, com densidade de 70-80 sementes viáveis por metro. A emergência das plantas ocorreu dia 06/12/2005.

Nas adubações de cobertura, o adubo foi distribuído sobre a superfície do solo ao lado e aproximadamente 10 $\mathrm{cm}$ das fileiras de plantas. O controle das plantas daninhas foi realizado mediante uma capina manual aos 12 DAE. Durante o desenvolvimento da cultura não foi realizado nenhum outro trato cultural. A colheita foi realizada quando mais de $2 / 3$ das espiguetas apresentavam coloração amarelo-clara ou creme, caracterizando a maturidade.

As avaliações de qualidade de sementes foram realizadas no período de março a agosto de 2006, utilizando as sementes produzidas no ensaio descrito acima.

Foram realizadas as seguintes avaliações: massa de 1000 grãos: foi determinada mediante coleta ao acaso e pesagem de duas amostras de 1.000 grãos de cada parcela (valores foram corrigidos para $0,13 \mathrm{~kg} . \mathrm{kg}^{-1}$ ); germinação: conduzido com quatro repetições de 100 sementes por tratamento, distribuídas em caixas gerbox sobre três folhas de papel germitest, umedecido com 2,5 vezes a sua massa com água destilada, colocadas no germinador regulado com temperatura constante de $25^{\circ} \mathrm{C}( \pm 2)$, umidade relativa do ar de $80 \%( \pm 5)$, com fotoperíodo de doze horas. As contagens foram realizadas aos três e aos sete dias após a semeadura, de acordo com os critérios estabelecidos nas Regras para Análise de Sementes (Brasil, 1992); primeira contagem: realizada em conjunto com o teste de geminação, determinando-se a percentagem de plântulas normais no terceiro dia após a sua instalação; envelhecimento acelerado: conduzido conforme descrição de Marcos Filho (1999) modificado. Em caixas plásticas, contendo uma lâmina de $40 \mathrm{~mL}$ água, as sementes foram dispostas sobre a superfície de uma tela, posicionada acima da lâmina de água, mantidas em estufa a $42^{\circ} \mathrm{C}$, por 36 horas. Após esse período, foi conduzido o teste de germinação, com quatro repetições de 50 sementes por tratamento, e a contagem foi realizada aos sete dias após a semeadura, de acordo com os critérios estabelecidos nas Regras para Análise de Sementes (Brasil, 1992); teste de frio com solo: conduzido segundo Marcos Filho (2005) modificado. Em caixas plásticas tipo gerbox, 
com quatro repetições de 50 sementes por tratamento, utilizando como substrato duas folhas de papel germitest cobertas com solo, onde as sementes foram semeadas e cobertas por uma fina camada de solo, e posteriormente foram colocadas em geladeira a $10{ }^{\circ} \mathrm{C}$ por sete dias. Após este período, as caixas foram mantidas em germinador regulado à temperatura de $25^{\circ} \mathrm{C}( \pm 2)$, onde permaneceram por sete dias, quando foi determinada a percentagem de plântulas normais de acordo com os critérios estabelecidos nas Regras para Análise de Sementes (Brasil, 1992); condutividade elétrica: foi conduzido conforme o método padrão descrito por Marcos Filho (2005), onde as quatro repetições de 50 sementes por tratamento tiveram sua massa determinada previamente. Após determinar a massa de cada amostra as sementes foram colocadas em copos plásticos contendo $75 \mathrm{~mL}$ de água deionizada e mantidas em germinador a temperatura de $25^{\circ} \mathrm{C}( \pm 2)$, com fotoperíodo de 12 horas, durante 24 horas. Decorrido esse período, a condutividade da solução foi determinada com o uso de um condutivímetro de marca MARCONI/Modelo CA 150. Os valores obtidos no aparelho foram divididos pela massa da amostra ( $\mathrm{g}$ ) e os resultados expressos em $\mu \mathrm{S} . \mathrm{cm}^{-1} \cdot \mathrm{g}^{-1}$ de sementes; índice de velocidade de emergência (IVE): foi realizado a partir da semeadura de quatro repetições de 50 sementes por tratamento em solo umedecido, conduzido em condições ambientais, distribuídas em sulcos e cobertas com uma fina camada de terra, contando-se diariamente, a partir do início da emergência, o número de plântulas que atingiram um estádio pré-determinado, até que o processo se estabilizasse. O cálculo do índice de velocidade de emergência foi realizado através da fórmula Maguire (1962). E para cada repetição, calculou-se o IVE, empregando a fórmula, onde a média aritmética das quatro repetições foi o índice; emergência de plântulas em campo: conduzido juntamente com o índice de velocidade de emergência. As avaliações foram realizadas aos 21 dias após a semeadura, determinando-se as porcentagens de emergência de plântulas (Nakagawa, 1994) e, sanidade: a qualidade sanitária das sementes de painço foi determinada através do método do "Blottertest", sem assepsia. Para isto, 4 repetições de 25 sementes foram acondicionadas em caixas gerbox, contendo três folhas de papel germitest previamente umedecidas em água deionizada e incubadas em câmara de crescimento por sete dias à temperatura de $25^{\circ} \mathrm{C}( \pm 2)$, sob fotoperíodo de 12 horas. Após esse período de incubação as sementes foram examinadas, individualmente, sob microscópio estereoscópico e/ou microscópio ótico, computando-se a porcentagem de incidência de fungos. A identificação foi realizada com base nas suas características morfológicas e com o auxílio de literatura específica.

Os dados obtidos foram submetidos à análise de variância. As médias referentes à época de aplicação de $\mathrm{N}$ foram comparadas pelo teste Tukey a $5 \%$ de probabilidade, enquanto os efeitos das doses de $\mathrm{N}$ foram avaliados pela análise de regressão, adotando-se como critério para escolha do modelo a magnitude dos coeficientes de regressão significativos ao nível de $5 \%$.

\section{RESULTADOS E DISCUSSÃO}

As doses e as épocas de aplicação do $\mathrm{N}$ em cobertura não interferiram na massa de mil sementes (Tabela 1). Nakagawa et al. (2000) e Jornada et al. (2005) também não verificaram efeito do $\mathrm{N}$ na massa de grãos de aveia preta e milheto, respectivamente.

A avaliação da qualidade fisiológica das sementes de painço foi determinada através dos testes de germinação e vigor. Os valores de germinação, expressos pela porcentagem de plântulas normais, não apresentaram diferenças significativas em função das doses e épocas de aplicação de $\mathrm{N}$ em cobertura (Tabela 1), assim como o observado por Silva et al. (2004), trabalhando com diferentes níveis de $\mathrm{N}$ em cobertura sobre a qualidade de sementes de duas cultivares de painço. A não influência da adubação nitrogenada sobre a germinação também foi observada em outras culturas tais como: aveia-preta (Nakagawa et al., 2000; Silva et al., 2001); aveia branca (Kolchinski e Schuch, 2004). Também em capim-ramirez, Mecelis et al. (1991), não observaram relação entre o aspecto nutricional e a qualidade fisiológica das sementes (germinação).

De acordo com a Portaria $n^{\circ} 381 / 98$ do Ministério da Agricultura que estabelece, em todo território nacional, os padrões de sementes de gramíneas e leguminosas forrageiras o painço não está entre as gramíneas relacionadas, mas se enquadra no item: Demais gramíneas, as quais não apresentam porcentagem de germinação (Brasil, 1998).

O painço (Panicum miliaceum L.) e o capim-colonião (Panicum maximum Jacq.) são gramíneas que pertencem ao mesmo gênero, e para esta o padrão de germinação é de 40\% (Brasil, 1998). Para o painço o menor valor encontrado foi de $66,5 \%$ quando não houve adubação nitrogenada (Tabela 1), e esse valor demonstra que sua germinação está acima do padrão estabelecido para outra espécie do mesmo gênero. 
TABELA 1. Massa de mil sementes (MS), porcentagem de germinação (G), primeira contagem de germinação (PCG), envelhecimento acelerado (EA), teste de frio (TF), condutividade elétrica (CE), índice de velocidade emergência (IVE) e emergência campo (EC) em função da aplicação de doses de nitrogênio em cobertura aos 14 ou 28 DAE

\begin{tabular}{|c|c|c|c|c|c|c|c|c|}
\hline Tratamentos & $\begin{array}{l}\text { MS } \\
(\mathrm{g})\end{array}$ & $\begin{array}{c}\mathrm{G} \\
(\%)\end{array}$ & $\begin{array}{c}\text { PCG } \\
(\%)\end{array}$ & $\begin{array}{l}\text { EA } \\
(\%)\end{array}$ & $\begin{array}{l}\mathrm{TF} \\
(\%)\end{array}$ & $\begin{array}{c}\mathrm{CE} \\
\left(\mu \mathrm{cm} \mathrm{g}^{-1}\right)\end{array}$ & IVE & $\begin{array}{l}\mathrm{EC} \\
(\%)\end{array}$ \\
\hline \multicolumn{9}{|l|}{ Época } \\
\hline $14 \mathrm{DAE}$ & $3,85 \mathrm{a}$ & $72,7 \mathrm{a}$ & $61,9 a$ & $79,7 \mathrm{a}$ & $56,3 \mathrm{a}$ & $83,7 \mathrm{a}$ & $4,34 \mathrm{~b}$ & $70,7 b$ \\
\hline $28 \mathrm{DAE}$ & $3,92 \mathrm{a}$ & $69,7 \mathrm{a}$ & $55,5 \mathrm{a}$ & $87,1 \mathrm{a}$ & $60,1 \mathrm{a}$ & $78,8 \mathrm{a}$ & $5,46 a$ & $78,3 \mathrm{a}$ \\
\hline \multicolumn{9}{|l|}{ Dose $\left(\mathrm{kg} \mathrm{ha}^{-1}\right)$} \\
\hline 0 & 3,88 & 66,5 & 52,3 & 91,3 & 60,0 & 82,6 & 4,29 & 67,3 \\
\hline 30 & 4,12 & 73,1 & 64,3 & 85,3 & 58,8 & 80,9 & 4,76 & 72,5 \\
\hline 60 & 3,80 & 78,8 & 65,5 & 78,5 & 54,3 & 81,0 & 5,41 & 81,3 \\
\hline 120 & 3,74 & 66,6 & 52,9 & 78,5 & 59,8 & 80,7 & 5,14 & 77,0 \\
\hline Regressão & ns & ns & ns & $\mathrm{ns}$ & $\mathrm{ns}$ & $\mathrm{ns}$ & ns & $*$ \\
\hline Interação E x D & ns & ns & $*$ & $*$ & ns & $\mathrm{ns}$ & $\mathrm{ns}$ & $*$ \\
\hline $\mathrm{CV}(\%)$ & 11,3 & 19,7 & 22,5 & 13,3 & 25,8 & 11,2 & 20,8 & 13,5 \\
\hline
\end{tabular}

Médias seguidas pela mesma letra na coluna, para o fator época, não diferem entre si pelo teste de Tukey, no nível de $5 \%$ de probabilidade. ns e *: não significativo e significativo a $5 \%$ de probabilidade. Para EC, médias seguidas pela mesma letra na coluna, para o fator época, não diferem entre si pelo teste de Tukey, ao nível de $10 \%$ de probabilidade. *: significativo a $10 \%$ de probabilidade.

Os testes de vigor são realizados com o objetivo de verificar o potencial de emergência de plântulas no campo, em condições favoráveis e desfavoráveis. $\mathrm{Na}$ primeira contagem da germinação observou-se aumento no vigor das plântulas com a elevação das doses de $\mathrm{N}$ até $62,82 \mathrm{~kg}$. ha $^{-1}$, aplicados aos $14 \mathrm{DAE}$, enquanto aos $28 \mathrm{DAE}$, não houve efeito significativo (Figura 1A). Entretanto, Oliveira et al. (2001), em sementes de feijão-caupi, observaram aumento linear com a elevação das doses de N. De acordo com Nakagawa (1994) as amostras que apresentam maior porcentagem de plântulas normais na primeira contagem são as mais vigorosas.

O efeito positivo da adubação nitrogenada observado sobre o vigor das sementes de painço (primeira contagem), foi contraditório ao observado por Crusciol et al. (2003) em feijão e Schuch et al. (1999) em aveia preta, os quais ao avaliarem o efeito do $\mathrm{N}$ no vigor de sementes constataram que a porcentagem de plântulas na primeira contagem foi menor quando realizaram adubação nitrogenada. Outros trabalhos, entretanto não observaram interferência da adubação nitrogenada sobre o vigor expresso pelo teste de primeira contagem. Silva et al. (2001) ao avaliarem dosagens e épocas de aplicação de $\mathrm{N}$ e Nakagawa et al. (2000) ao avaliarem doses de $\mathrm{N}$ em cobertura, ambos com sementes de aveia, constaram que não houve efeito sobre o vigor.

De acordo com a Figura 1B, observa-se que a qualidade fisiológica das sementes de painço analisadas através do teste de envelhecimento acelerado demonstrou diferença significativa, pois conforme se eleva as doses de $\mathrm{N}$ aos 14 DAE a porcentagem de germinação reduz linearmente. Estes resultados foram contrários ao trabalho de Farinelli et al. (2006), em sementes de feijão, os quais observaram que a adubação nitrogenada em cobertura promoveu acréscimos no vigor das sementes de forma quadrática. Vieira, et al. (1995) avaliando a qualidade fisiológica de sementes de trigo observaram que a dose de $120 \mathrm{~kg}$. ha-1 de $\mathrm{N}$ em uma única aplicação na cultura do trigo proporcionou maior germinação no envelhecimento acelerado das sementes obtidas. No entanto, o envelhecimento acelerado avaliado aos 28 DAE, demonstrou que a adubação nitrogenada não apresentou efeito significativo sobre a germinação das sementes (Figura 1B), corroborando com os trabalhos de Costa et al. (1983) em arroz, Nakagawa et al. (2000) em aveia-preta, Kolchinski e Schuch (2004) em aveiabranca os quais também não observaram diferença significativa na germinação das sementes submetidas ao mesmo teste. 

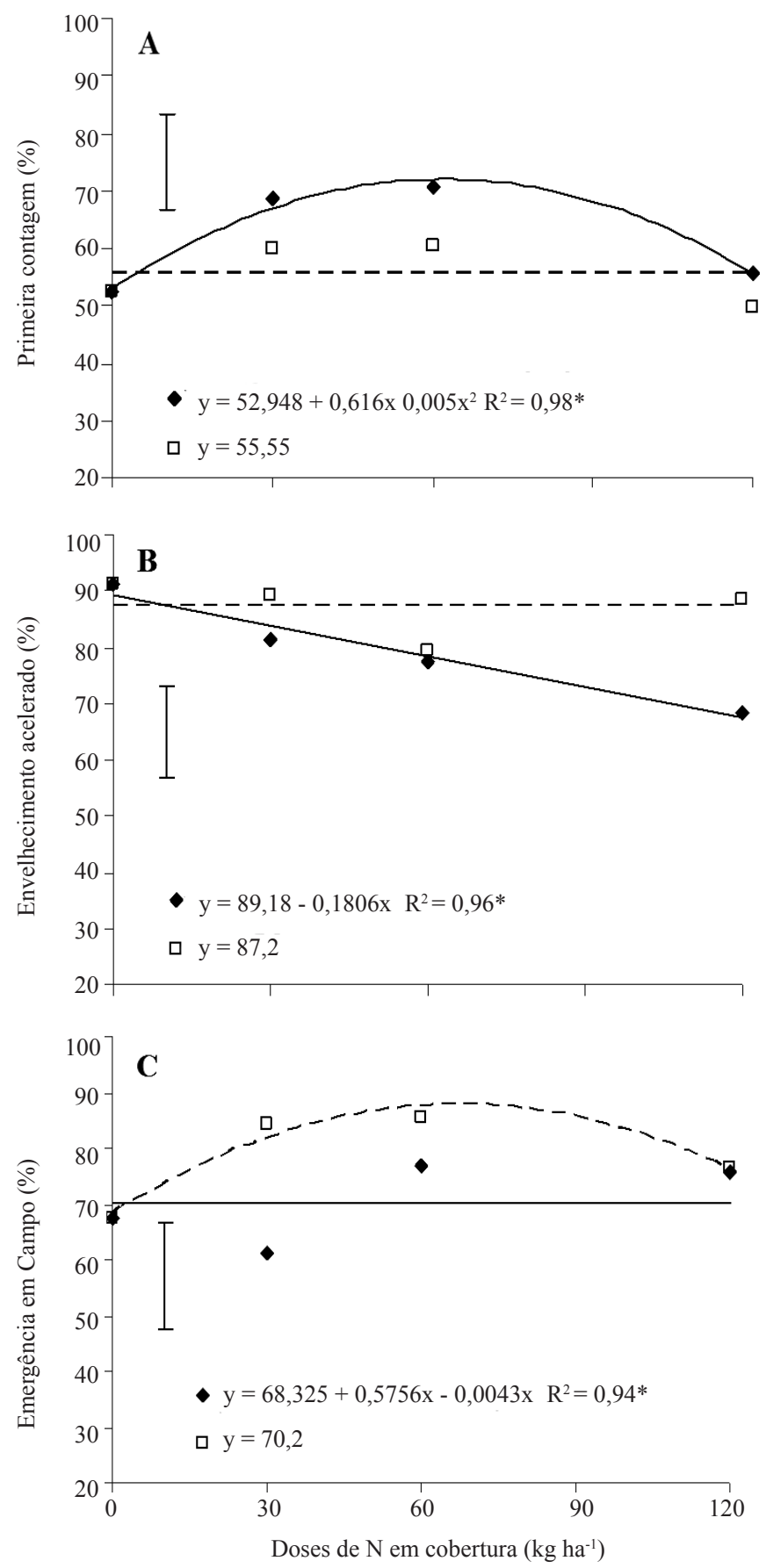

FIGURA 1. Porcentagem de germinação na primeira contagem (A), envelhecimento acelerado das sementes (B) e emergência em campo de plântulas $(C)$ de painço em função de doses de nitrogênio em cobertura aos $(\diamond)$ 14 ou (口) 28 DAE. * e ns são: significativo a $5 \%$ e não-significativo pelo teste $F$. Barras verticais indicam o valor de DMS do teste Tukey $(\mathbf{P}=\mathbf{0 , 0 5})$.
O resultado do teste de frio não indicou diferença estatística entre os tratamentos, mas permitiu verificar diferenciação da qualidade em relação ao teste de germinação, demonstrando que essa cultura apresenta suscetibilidade a baixas temperaturas (Tabela 1). A combinação de baixas temperaturas e excesso de água no solo pode provocar efeitos diretos às sementes, reduzindo a velocidade de emergência e favorecendo o desenvolvimento de microrganismos patogênicos, portanto, as sementes resistentes a essas condições desfavoráveis são mais vigorosas (Cicero e Vieira, 1994).

$O$ teste de condutividade elétrica também não apresentou diferença significativa entre os tratamentos (Tabela 1). Portanto, se mantiveram dentro de um mesmo padrão, o qual sugere não ter havido modificações significativas nas sementes capazes de proporcionar uma lixiviação de eletrólitos diferenciada, em função das doses de $\mathrm{N}$ aplicados em cobertura, em diferentes épocas. Os resultados são coerentes com os trabalhos de Farinelli et al. (2006) e de Crusciol et al. (2003), os quais não observaram diferenças significativas em relação ao efeito do $\mathrm{N}$ no teste de condutividade elétrica em sementes de feijão. Nakagawa et al. (2000), estudando o efeito do $\mathrm{N}$ na condutividade elétrica de aveia preta em dois experimentos, verificaram efeito apenas em um deles, com redução da condutividade elétrica até a dose de $40 \mathrm{~kg} \mathrm{ha}^{-1} \mathrm{de} \mathrm{N}$.

Quanto ao IVE, verifica-se que houve efeito significativo apenas da época de aplicação do N, sendo que o maior IVE foi proporcionado pela aplicação do $\mathrm{N}$ aos 28 DAE, indicado maior vigor das sementes produzidas nesse tratamento (Tabela 1). Nakagawa et al. (2000) avaliando adubação nitrogenada em aveia-preta, em duas condições de fertilidade de solo constataram que não houve efeito as doses de N sobre o IVE.

Semelhante ao observado para o IVE, a aplicação de N aos 28 DAE também proporcionou maior porcentagem de emergência em campo(Tabela 1). Além disso, houve interação significativa para essa variável, sedo que a aplicação de $\mathrm{N}$ aos 28 DAE proporcionou aumento da emergência em campo de plântulas até a dose máxima estimada de $67 \mathrm{~kg}$. ha-1 $.67 \mathrm{Kg}$. ha $^{-1}$ (Figura 1C). Em aveia-preta, Nakagawa et al. (2000), e em milheto, Jornada et al. (2008) também não verificaram efeito do $\mathrm{N}$ sobre na porcentagem de emergência em campo. Condé e Garcia (1988a), avaliando doses de $\mathrm{N}$ e épocas de aplicação em capim-colonião, constataram maior emergência de plântulas, quando o $\mathrm{N}$ foi aplicado mais tardiamente, ou seja, no início do primórdio floral. Cani (1980) verificaram que o $\mathrm{N}$ aplicado a braquiária aumentou a emergência de plântula, bem como a velocidade de germinação. 
A utilização de sementes livres de fitopatógenos no estabelecimento da culturaé de extremaimportância, sendo que, práticas culturais, incluindo o manejo da adubação nitrogenada, podem influenciar na contaminação/ infecção de sementes obtidas. Na avaliação da qualidade sanitária das sementes, foi constatada a presença de vários patógenos (Figura 2). Os microrganismos que apresentaram maior incidência foram: Cladosporium spp. (10,38\%), Curvularia spp. (9,50\%), Phoma spp. (7,5\%), Bipolaris spp. (2,63\%), Fusarium spp. (2,25\%), Alternaria spp. (0,62\%) e Stigmina spp. (0,51\%), além da presença em menor porcentagem de Penicillium spp. e Rhizoctonia spp. Marschner (1995) relata que as concentrações elevadas de $\mathrm{N}$ reduzem a produção de compostos fenólicos, que possuem ação fungistática, e a lignificação das folhas, diminuindo a resistência aos patógenos obrigatórios, além disso, o $\mathrm{N}$ pode aumentar a concentração de aminoácidos e amidas nas células que favorece o desenvolvimento de fungos. Porém, não foi observado efeito significativo de doses e épocas de aplicação da adubação nitrogenada na incidência de patógenos nas sementes. Em arroz, aplicação excessiva de N (200 kg. ha $\left.{ }^{-1}\right)$ aumenta a incidência de Alternaria padwickii, e níveis de $\mathrm{N}$ superiores a $100 \mathrm{~kg}$. ha-1 aumentam a incidência de Curvularia lunata e Phoma sorghina (Agarwal et al., 1975).

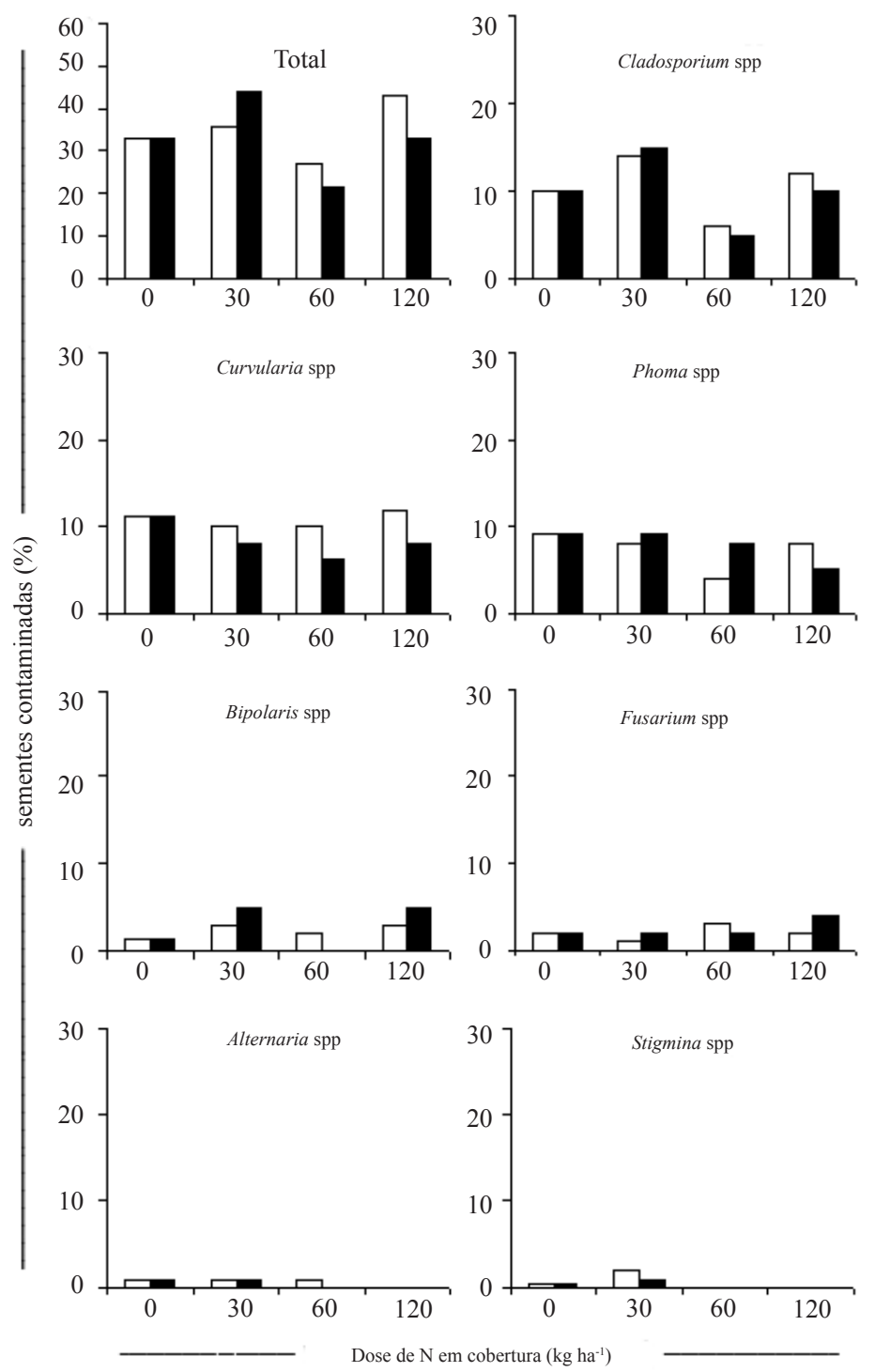

FIGURA 2. Porcentagens de sementes de painço contaminadas com fungos em função da aplicação de doses de nitrogênio em cobertura aos (ロ) 14 ou (D) 28 DAE. 


\section{CONCLUSÕES}

A aplicação de $\mathrm{N}$ afeta positivamente o vigor das sementes, expresso pelos testes de envelhecimento acelerado e emergência em campo.

A aplicação de $\mathrm{N}$ aos $28 \mathrm{DAE}$ da cultura do painço proporciona maior IVE e porcentagem de emergência em campo.

A sanidade de sementes de painço não é influenciada pelas doses e épocas de aplicação da adubação nitrogenada.

\section{REFERÊNCIAS}

AGARWAL, V.K.; SINGH, O.V.; MODGAL, S.C. Influence of different doses of nitrogen and spacing on seed-borne infection of rice. Indian Phytopathology, v.28, n.1, p.38-40, 1975.

BRASIL. Ministério da Agricultura e Reforma Agrária. Secretaria Nacional de Defesa Agropecuária. Departamento Nacional de Produção Vegetal. Coordenação de Laboratório Vegetal. Regras para análise de sementes. Brasília, DF, 1992. 365p.

BRASIL. Portaria ${ }^{\circ}$ 381, de 05 de Agosto de 1998. Diário Oficial da União, Brasília, DF, 06 ago. 1998, Seção 1, p.43.

CANI, P.C. Influência do nitrogênio, cortes e épocas de colheita sobre a produção e qualidade das sementes do capim braquiária (Brachiaria decumbens Stapf). 1980. 62f. Tese Mestrado Viçosa, Universidade Federal de Viçosa, Viçosa, 1980.

CARVALHO, N.M. NAKAGAWA, J. Sementes: ciência, tecnologia e produção. Jaboticabal: FUNEP, 2000, 588p.

CICERO, S.M.; VIEIRA, R.D. Teste de frio. In: VIEIRA, R.D.; CARVALHO, N.M. Testes de vigor em sementes. Jaboticabal: FUNEP, 1994, p.151-164.

CONDÉ, A.R.; GARCIA, J. Efeito de níveis e épocas de aplicação de nitrogênio na produção e qualidade das sementes de capim-colonião. Revista Brasileira de Sementes, v.10, n.1, p.33-42, 1988a.

CONDÉ, A.R.; GARCIA, J. Influência de níveis e épocas de aplicação de nitrogênio sobre o rendimento, qualidade e componentes da produção de sementes do capimbraquiária. Revista Brasileira de Sementes, v.10, n.1, p.63-71, 1988b.
COSTA, N.P.; GOMES, A.S.; PESKE, S.T.; POPINIGIS, F.; ZONTA, E.P. Influência da adubação nitrogenada sobre o vigor e conteúdo de proteínas de sementes de quatro cultivares de arroz irrigado. Revista Brasileira de Sementes, v.5, n.1, p.31-42, 1983.

CRUSCIOL，C.A.C.; LIMA，E.D.; ANDREOTTI, M.; NAKAGAWA, J.; LEMOS, L.B.; MARUBAYASHI, O.M. Efeito do nitrogênio sobre a qualidade fisiológica, produtividade e características de sementes de feijão. Revista Brasileira de Sementes, v.25, n.1, p.108-115, 2003.

DIDONET, A.D. Revisão sobre aspectos fisiológicos envolvendo qualidade e teor protéico do grão de trigo. In: SÁ, M.E.; BUZZETTI, S. Importância da adubação na qualidade dos produtos agrícolas. São Paulo: Ícone, cap.15, p.249-255, 1994.

FARINELLI, R.; LEMOS, L.B.; CAVARIANI, C.; NAKAGAWA, J. Produtividade e qualidade fisiológica de sementes de feijão em função de sistemas de manejo de solo e adubação nitrogenada. Revista Brasileira de Sementes, v.28, n.2, p.102-109, 2006.

FURUHASHI, S. Efeito de doses e de época de aplicação de nitrogênio na cultura do painço em sucessão a mucuna preta. 1995, 31f. Monografia (Graduação em Agronomia) Faculdade de Ciências Agrárias e Veterinárias, Universidade Estadual Paulista, Jaboticabal, 1995.

JORNADA, J.B.J.; MEDEIROS, R.B.; PEDROSO, C.E.S.; SAIBRO, J.C.; SILVA, M.A. Efeito da irrigação, épocas de corte da forragem e doses de nitrogênio sobre o rendimento de sementes de milheto. Revista Brasileira de Sementes, v.27, n.2, p.50-58, 2005.

JORNADA, J.B.J.; MEDEIROS, R.B.; PEDROSO, C.E.S.; SAIBRO, J.C.; SILVA, M.A. Efeito da irrigação, épocas de corte da forragem e doses de nitrogênio sobre a qualidade de sementes de milheto (Pennisetum americanum (L.) Leeke). Revista Brasileira de Sementes, v.30, n.3, p.10-15. 2008.

KALINOVA, J.; MOUDRY, J. Content and quality of protein in proso millet (Panicum miliaceum L.) varieties. Plant Foods for Human Nutrition, v.61, n.1, p.45-49, 2006.

KOLCHINSKI, E.M.; SCHUCH, L.O.B. Relação entre a adubação nitrogenada e a qualidade de grãos e de sementes em aveia branca. Ciência Rural, v.34, n.2, p.379-383, 
2004.

LIMA, E.V.; CAVARIANI, C.; LIMA, P.L.; CRUSCIOL, C.A.C.; NAKAGAWA, J.; VILLAS BOAS, R.L. Qualidade fisiológica de sementes de painço (Panicum dichotomiflorum Michx.) em função do tempo de mistura com o superfosfato triplo. Cultura Agronômica, v.9, n.1, p.177-189, 2000.

MAGUIRE, J.D. Speed of germination - Aid selection and evaluation or seedling emergence and vigor. Crop Science, v.2, n.2, p.176-177, 1962.

MALAVOLTA, E.; VITTI, G.C.; OLIVEIRA, S.A. Avaliação do estado nutricional de plantas: princípios e aplicações. Piracicaba: Potafos, 1997. 308p.

MARCOS FILHO, J. Fisiologia de sementes de plantas cultivadas. Piracicaba: FEALQ, v.12, 2005, 495p.

MARCOS FILHO, J. Teste de envelhecimento acelerado. In: KRZYZANOWSKI, F.C.; VIEIRA, R.D.; FRANÇA NETO, J.B. (Ed.). Vigor de sementes: conceitos e testes. Londrina: ABRATES, 1999, p.3.1-3.24.

MARSCHNER, H. Mineral nutrition of higher plants. 2.ed. San Diego: Academic Press, 1995, 889p.

MECELIS, N.R.; SCHAMMASS, E.A.; DIAS, L.M.G.S. Efeitos de adubação nitrogenada sobre a germinação de sementes de Capim Ramirez. Revista Brasileira de Sementes, v.13, n.1, p.53-57, 1991.

MEIRELES, R.C.; SILVA; R.F.; ARAÚJO, E.F. REIS, L.S.; LYRA, G.B.; MARINHO, A.B. Influência do nitrogênio e das lâminas de irrigação na qualidade fisiológica das sementes de mamoeiro. Revista Brasileira de Sementes, v.31, n.1, p.216-221, 2009.

NAKAGAWA, J. Teste de vigor baseados na avaliação de plântulas. In: VIEIRA, R.D.; CARVALHO, N.M. Testes de vigor em sementes. Jaboticabal: FUNEP, 1994, p.4986.

NAKAGAWA, J.; CAVARIANI, C.; MACHADO, J.R. Adubação nitrogenada no perfilhamento da aveiapreta em duas condições de fertilidade do solo. Pesquisa Agropecuária Brasileira, v.35, n.6, p.1071-1080, 2000.

OLIVEIRA, A. P.; BRUNO, R.L.A.; BRUNO, G.B.; ALVES, E.U.; PEREIRA, E.L. Produção e qualidade de sementes de feijão-caupi (Vigna unguiculata L.) (Walp), em função de doses e formas de aplicação de nitrogênio.
Revista Brasileira de Sementes, v.23, n.2, p.215-221, 2001.

OLIVEIRA, A.P.; PEREIRA, E.L.; BRUNO, R.L.A.; ALVES, E.U.; COSTA, R.F.; LEAL, F.R.F. Produção e qualidade fisiológica de sementes de feijão-vagem em função de fontes e doses de nitrogênio. Revista Brasileira de Sementes, v.25, n.1, p.49-55, 2003.

POPINIGIS, F. Fisiologia da semente. 2.ed. Brasília, DF. AGIPLAN, 1985, 289p.

RAIJ, B.V.; ANDRADE, J.C.; CANTARELLA, H.; QUAGGIO, J.A. Análise química para avaliação da fertilidade de solos tropicais. Campinas: Instituto Agronômico, 2001. 28p.

SÁ, M.E. Importância da adubação na qualidade de semente. In: SÁ, M.E.; BUZZETI, S. (Ed.). Importância da adubação na qualidade dos produtos agrícolas. São Paulo: Ícone, 1994. p.65-98.

SCHUCH, L.O.B.; NEDEL, J.L.; MAIA, M.S.; ASSIS, F.N. Vigor de sementes e adubação nitrogenada em aveia-preta (Avena strigosa Schreb). Revista Brasileira de Sementes, v.21, n.2, p.127-134, 1999.

SILVA, R.H.; ZUCARELI, C.; NAKAGAWA, J.; SILVA, R.A.; CAVARIANI, C. Doses e épocas de aplicação do nitrogênio na produção e qualidade de sementes de aveiapreta. Revista Brasileira de Sementes, v.23, n.2, p.51-55, 2001.

SILVA, T.R.B.; SORATTO, R.P.; LIMA, E.V.; TAVARES, C.A. Adubação nitrogenada em cultivares de painço: qualidade fisiológica, $\mathrm{N}$ total e proteína nas sementes. Cultura Agronômica, v.13, n.1, p.69-79, 2004.

SORATTO, R.P.; LIMA, E.V.; SILVA, T.R.B.; BOARO, C.S.F.; CATANEO, A.C. Nitrogen fertilization of fall panicum cultivars (Panicum dichotomiflorum Michx.): biochemical and agronomical aspects. Scientia Agricola, v.61, n.1, p.82-87, 2004.

SORATTO, R.P.; CARDOSO, S.M.; SILVA, A.H.; COSTA. T.A.M.; PEREIRA, M.; CARVALHO, L.A. Doses e épocas de aplicação de nitrogênio em cobertura na cultura do painço (Panicum miliaceum L.). Ciência e Agrotecnologia, v.31, n.6, p.1661-1667, 2007.

TEIXEIRA, I.R.; BORÉM, A.; ARAÚJO, G.A.A.; ANDRADE, M.J.B. Teores de nutrientes e qualidade 
fisiológica de sementes de feijão em resposta à adubação foliar com manganês e zinco. Bragantia, v.64, n.1, p.8388, 2005.

TOLEDO, M.Z.; FONSECA, N.R.; CESAR, M.L.; SORATTO, R.P.; CAVARIANI, C.; CRUSCIOL, C.A.C. Qualidade fisiológica e armazenamento de sementes de feijão em função da aplicação tardia de nitrogênio em cobertura. Pesquisa Agropecuária Tropical, v.39, n.2, p.124-133, 2009.

VIEIRA, R.D.; FORNASIERI FILHO, D.; MINOHARA, L.; BERGAMASCHI, M.C.M. Efeito de doses e épocas de aplicação de nitrogênio em cobertura na produção e na qualidade fisiológica de sementes de trigo. Científica, v.23, n.2, p.257-264, 1995.

ZANCANELLA, E.F.; BONATI, J.L.; MARTUCCI, L.M.V. Novos cultivares de painço. Disponível em: $<$ www.cati.sp.gov.br/novacati/tecnologias/painco/novos cultivares.htm>. Acesso em: 20 mar. 2006.

ZANCANELLA, E.F.; BONATTI, J.L.; MARTUCCI, L.M.V. Cultura do painço: informações práticas. Campinas: CATI, 2003. 4p. (Folheto). 